\title{
Enhanced Electrochemical and Physical Properties of Ag/AgCl Planar Reference Electrodesin Potentiometric Sensors by Graphite Oxide Layer
}

\author{
Tung Son Vinh Nguyen, Tien Minh Huynh, Tin Chanh Duc Doan and Chien Mau Dang \\ Community 6, Linh Trung Ward, Thu Duc District, Ho Chi Minh City 800010, Vietnam
}

\begin{abstract}
The most common reference electrode (RE) which is used in electrochemical measurements is the $\mathrm{Ag} / \mathrm{AgCl}$ electrode. In this study, we present a novel solid-state $\mathrm{Ag} / \mathrm{AgCl}$ planar electrode that was coated with a thin layer of Graphite Oxide (GO) as a protective layer. $\mathrm{The} \mathrm{Ag} / \mathrm{AgCl}$ planar electrode was fabricated by using the photolithography and lift-off method combined with the $\mathrm{Ag}\left[\mathrm{NH}_{3}\right]_{2} \mathrm{Cl}$ complex. The GO was produced by Hummer's method and was deposited on top of the $\mathrm{Ag} / \mathrm{AgCl}$ layer by drop-casting method. The layers of the fabricated reference electrode were characterized by micro Raman spectroscopy, Scanning Electron Microscopy (SEM) and Energy-dispersive X-ray spectroscopy (EDX). The responding time of the planar electrode was short and the signal was more stable in comparison to the plain $\mathrm{Ag} / \mathrm{AgCl}$ electrode. The Open Circuit Potential (OCP) measurement with the fabricated electrode as the $\mathrm{RE}$ and the platinum electrode as the working electrode in electrolyte solutions which had various $\mathrm{pH}$ values was performed with a linear response in $\mathrm{pH}$ ranges from $\mathrm{pH} 5$ to $\mathrm{pH} 8$ and the linear correlation coefficient $\left(\mathrm{R}^{2}=0.9899\right)$. Moreover, the coating of the GO layers also enhanced the durability of the modified electrode. The results showed that the modified $\mathrm{Ag} / \mathrm{AgCl}$ electrode with a thin layer $\mathrm{GO}$ as the protective layer could be used as plana REs for the potentiometric sensors.
\end{abstract}

Key words: Graphite oxide, potentiometric sensor, $\mathrm{Ag} / \mathrm{AgCl}$ reference electrode.

\section{Introduction}

Nowadays, one of the most common topics which attract lots of attention of researchers is development of the electrochemical sensors that are fabricated by using the micro-fabrication techniques [1]. It is due to the advantages of the fabrication techniques such as easy process to make, effective cost and portability. In an electrochemical measuring system, a reference electrode plays an important role. There are many types of reference electrodes such as hydrogen, calomel, double junction, liquid junction or silver/silver chloride reference electrodes. The most popular material which is used to fabricate the RE is $\mathrm{Ag} / \mathrm{AgCl}$, thanks to its good properties for the electrochemical measurements. However, the

Corresponding author: Tin Chanh Duc Doan, Dr., research fields: conducting polymers, carbon nanotube, optoelectronic semiconductors, catalyst for fuel cell, environmental sensors. restrictions of the convention $\mathrm{Ag} / \mathrm{AgCl}$ electrodes are normally in macro scale and it cannot be applied in the micro-electrochemical sensors [2]. Therefore, many scientists have aimed to minimize the size or integrate the RE with other electrodes on the same platform for the biomedical or environmental purposes [2-7].

Normally, the $\mathrm{Ag} / \mathrm{AgCl}$ electrode is produced by coating a thin layer of $\mathrm{AgCl}$ on top of asilver wire. After that, it will be dipped into a saturate $\mathrm{KCl}$ solution as an electrolyte liquid. In order to fabricate the micro-scaled $\mathrm{Ag} / \mathrm{AgCl}$ electrode, there are numerous methods such as electrochemical coating, screen printing or thin film deposition... For example, an $\mathrm{Ag} / \mathrm{AgCl}$ thin film was fabricated by Suzuki and his colleagues by Ref. [8] using sputtering and electrochemical method. At first, a thin layer of silver $(300 \mathrm{~nm})$ was sputtered then a layer of $\mathrm{AgCl}$ was grown on top of that by using chrono-potentiometric technique with a constant current of $20 \mu \mathrm{A}$ [8]. 
Another example is Kim et al. [9], they deposited a silver layer $(1,000 \mathrm{~nm})$ on a glass surface by using sputtering technique. Then, the $\mathrm{Ag}$ layer was chlorinated by a drop of $\mathrm{FeCl}_{3} 50 \mathrm{mM}$ [9]. The same concept with Kim's is Huang et al. [10], they chlorinated the silver layer by using the electrochemical technique. The $\mathrm{AgCl}$ layer was formed by using constant voltage of $1.0 \mathrm{~V}$ with the chloride solution $0.1 \mathrm{M} \quad \mathrm{HCl}$ [10]. After the publication of Huang, lots of research on electrochemical methods has been performed with different chloride solutions $(\mathrm{HCl}, \mathrm{KCl}, \mathrm{NaCl}, \ldots)$ or different currents or voltages to grow the $\mathrm{AgCl}$ layer on top the Ag platform $[5,7,11,12]$. Some other studies preferred screen-printing technique due to its simplicity procedure. A quasi-reference electrode could be fabricated by printing all the components of the electrode step by step. For instant, on a polyester foil, Zielińska et al. [13] printed an ion-selective chloride electrode which contained silver contact, carbon and an insulating layer. Between each printing step, the ink layer was treated with different conditions like UV irradiation or heating to enhance the adhesion of each layer. Moreover, some studies proved that screen-printing techniques could combine with the electrochemical technique or it could be done with various type of ink (gel or paste) [14-16]. However, one of the disadvantages of this technique is the thickness of the printed layer. It is usually from several hundred micrometers to some millimeters. In addition, with this technique, many components are required for the paste formula, which results in less purity of the printed electrode. One common problem of the bare $\mathrm{Ag} / \mathrm{AgCl}$ electrodes is the self-degradation of electrode in solutions during electrochemical measurements. Hence, a protection layer is needed to coat on top of the $\mathrm{Ag} / \mathrm{AgCl}$ electrode in order to increase the durability of the RE. There are many types of the protection layer such as polymeric electrode [17, 18], nafion [9, 19], metallic layer [20] or agarose gel $[14,21]$.

In this study, graphite oxide produced by using Hummer's method was used as a protection layer for the specific fabricated $\mathrm{Ag} / \mathrm{AgCl}$ electrode. Finally, the thin layer of graphite oxide was deposited on top of the $\mathrm{Ag} / \mathrm{AgCl}$ layer to enhance its physical and electrochemical properties of the $\mathrm{Ag} / \mathrm{AgCl}$ planar electrode.

\section{Experiments}

\subsection{Materials}

The fabricated $\mathrm{Ag} / \mathrm{AgCl}$ electrode was fabricated by using sputtering and drop-casting a complex of $\mathrm{Ag}\left(\mathrm{NH}_{3}\right)_{2} \mathrm{Cl}$ solution reported in our other article [22].

Graphite powder $99 \%$, sulfuric acid $\left(\mathrm{H}_{2} \mathrm{SO}_{4}\right)$ $98 \%$, hydrochloric acid $(\mathrm{HCl}) 37 \%$, hydrogen peroxide $\left(\mathrm{H}_{2} \mathrm{O}_{2}\right) \quad 30 \%$, potassium permanganate $\left(\mathrm{KMnO}_{4}\right) 97 \%$ were purchased from Sigma-Aldrich, Germany. Deionized (DI) water was supplied by a DI
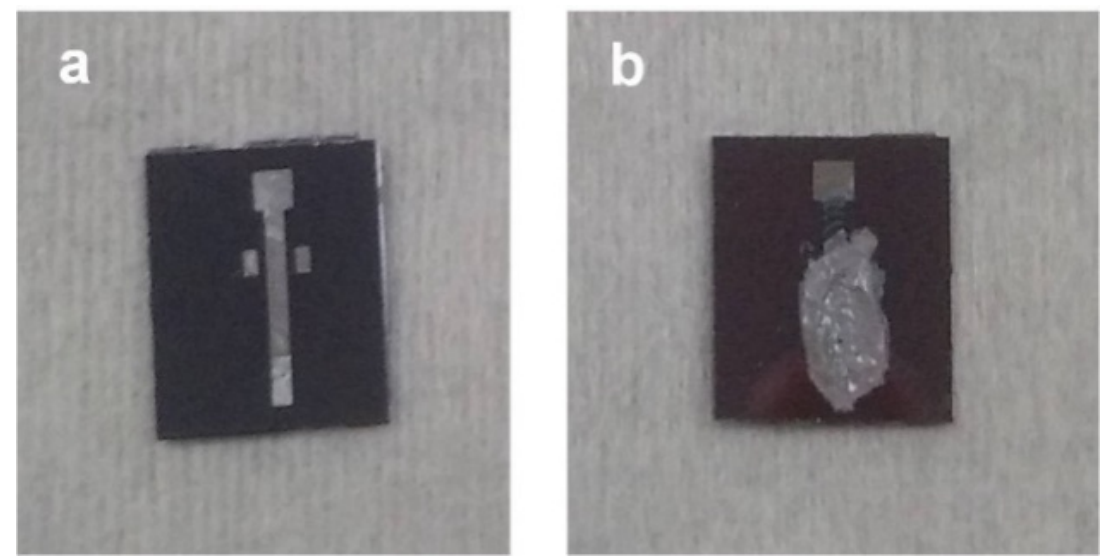

Fig. 1 The photos of the Ag electrode before (a) and after (b) being coated with the AgCl layer. 


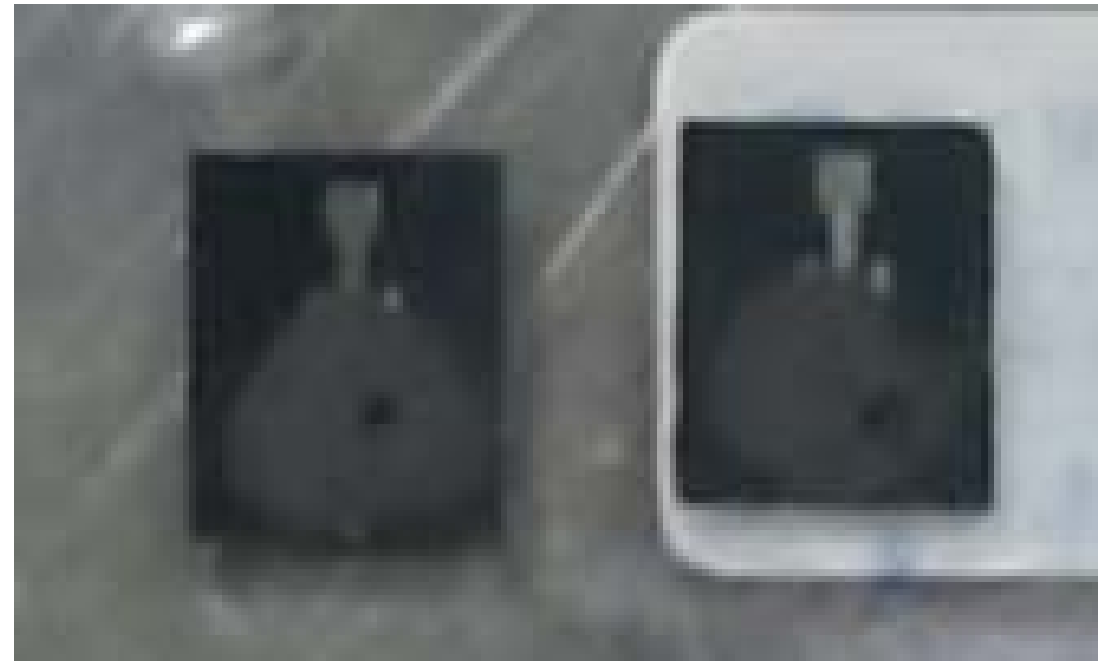

Fig. 2 The photo of the $\mathrm{Ag} / \mathrm{AgCl}$ electrode after being put on the GO protective layer.

system (Purelab Ultra, Elga Co., UK), the resistance of the outlet water was $18.2 \mathrm{MOhms}$. The $\mathrm{pH}$ buffer solutions from Hanna Instruments Vietnam were used as electrolyte in the electrochemical measurements.

\subsection{Process of Producing Graphite Oxide (GO) by Using Hummer's Method}

In a $100 \mathrm{~mL}$ flask, $1.5 \mathrm{~g}$ of graphite powder was added into $35 \mathrm{~mL}$ of concentrated $\mathrm{H}_{2} \mathrm{SO}_{4}$ and stirred with 150 r.p.m in 15 minutes. The flask was put in an ice bath to prevent the heat of the reaction. After that, $5 \mathrm{~g}$ of $\mathrm{KMnO}_{4}$ was slowly added into the flask. The whole solution was stirred with 250 r.p.m in 2 hours at $40{ }^{\circ} \mathrm{C}$. Then, $60 \mathrm{~mL}$ of DI water was poured in the flask and solution was continuously stirred for 15 more minutes. All the solution was transfered into a new $500 \mathrm{~mL}$ beaker and added in $100 \mathrm{~mL}$ of DI water, $15 \mathrm{~mL} \mathrm{H}_{2} \mathrm{O}_{2}$. The solution was kept stirring for further 30 minutes. At this stage, the color of the solution changed from dark brown to yellow. Next, the solution was washed with $50 \mathrm{ml}$ DI water and $40 \mathrm{~mL}$ $\mathrm{HCl} 37 \%$ and the solution was continuously stirred for next 2 hours. For the next step, $350 \mathrm{~mL}$ of DI water was added into the solution and the solution was stirred for the next 1 hour. After that, the solution was let settle down for 1 day in order to separate the liquid and solid phase inside the beaker. Finally, the liquid inside the beaker was dismissed. The yellow-brownish gel which stayed at the bottom of the beaker was the graphite oxide solution.

\subsection{Fabrication of Graphite Oxide and Ag/AgCl/GO Electrode}

The GO solution was diluted with DI water (1:100) then shaked well and drop-casted on the surface of the fabricated $\mathrm{Ag} / \mathrm{AgCl}$ electrode. After that, the $\mathrm{Ag} / \mathrm{AgCl} / \mathrm{GO}$ electrode was dried at $100{ }^{\circ} \mathrm{C}$ within 30 minutes (Fig. 2).

\subsection{Characterization of the $\mathrm{Ag} / \mathrm{AgCl} / \mathrm{GO}$}

\subsubsection{Characterization}

The surface morphology was observed with Field Emission Scanning Electron Microscopy-FE-SEM (SU8000, Hitachi, Japan). The composition of $\mathrm{Ag} / \mathrm{AgCl} / \mathrm{GOthin}$ film was detected by Energy Dispersive X-ray Spectroscopy (EDS), Micro Raman spectroscopy with Lab RAM 300 (Jobin Yvon, France).

\subsubsection{Potential Measurements}

The electrochemical properties of the fabricated $\mathrm{Ag} / \mathrm{AgCl} / \mathrm{GO}$ electrode were characterized by using Autolab PGSTST, 302N, Metrohm, the Netherlands. The Open Circuit Potential (OCP) in the $\mathrm{pH}$ buffer solutions was performed with the fabricated $\mathrm{Ag} / \mathrm{AgCl} / \mathrm{GO}$ electrode as the reference electrode. A thin film Pt $(0.5 \mathrm{~mm}$ in width and $1.5 \mathrm{~mm}$ in length) 
was used as a working electrode.

\section{Results and Discussion}

\subsection{Characterization of $\mathrm{GO}$ and $\mathrm{Ag} / \mathrm{AgCl} / \mathrm{GO}$}

The GO layer was formed neatly on top of the $\mathrm{Ag} / \mathrm{AgCl}$ surface. As shown in Fig. 3, it is clearly shown that the surface morphology of the fabricated $\mathrm{Ag} / \mathrm{AgCl} / \mathrm{GO}$ electrode is formed by multi-layers which lied on top of each other. The thickness of the GO multi-layer was approximately $300 \pm 20 \mathrm{~nm}$. On the other hand, the physical stability of the modified electrodes was tested. A quick test was carried out by immersing the modified electrode in DI water and $\mathrm{pH}$ 7 buffer solution for 24 hours. After one day, the surface of the modified $\mathrm{Ag} / \mathrm{AgCl} / \mathrm{GO}$ electrode was remained stable and was not damaged whereas the $\mathrm{Ag} / \mathrm{AgCl}$ electrode was stripped off from the platform just in less than 1 hour. It was proved that the GO layer enhanced the physical property (durability) of the fabricated $\mathrm{Ag} / \mathrm{AgCl}$ electrode.

Chemical analysis of the $\mathrm{Ag} / \mathrm{AgCl}$ layers fabricated on the $\mathrm{Si} / \mathrm{SiO}_{2}$ substrates was performed by using Energy Dispersive X-Ray Spectroscopy (EDX) with normal scan and mapping modes. The EDX results (Fig. 4) showed the peaks of the elements presented in the electrode, which are well-matched with the literature EDS results [17]. The elements such as Ag, $\mathrm{Cl}, \mathrm{C}$ and $\mathrm{O}$ were detected in the electrode. From this

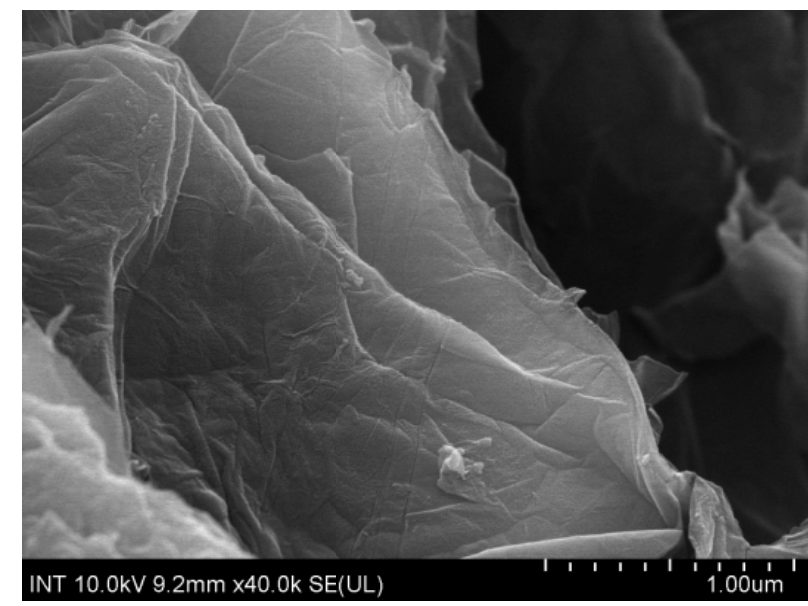

result, it can be said that a GO layer was formed on the surface of the $\mathrm{Ag} / \mathrm{AgCl}$ thin film and the $\mathrm{Ag} / \mathrm{AgCl}$ electrodes were produced with high purity.

Moreover, the change in the structure and the effect of interaction between each layer and element could also be obtained by using the Raman spectra (Fig. 5). The two identical peaks of the graphitic material (D and $\mathrm{G}$ bands) were found in $\mathrm{Ag} / \mathrm{AgCl} / \mathrm{GO}$ around $1,350 \mathrm{~cm}^{-1}$ and $1,590 \mathrm{~cm}^{-1}$, respectively [23].

\subsection{Electrochemical Properties}

\subsubsection{The Stability of the Fabricated $\mathrm{Ag} / \mathrm{AgCl} / \mathrm{GO}$} Electrode

One of the important factors of the electrochemical sensor performance is the long-term stability. The potential and the responding time of the fabricated electrode were observed in 5 days using a $3 \mathrm{M} \mathrm{KCl}$ solution (Fig. 6).

The potential of the fabricated electrode varied by approximately $0.05 \mathrm{mV}$. It proved that the potential of the electrode remained quite stable over the test period (5 days). Moreover, the potential signal became stable within $20 \mathrm{~s}$ after the electrode had been immersed into the solutions during each of the measurements. The results indicated that the fabricated $\mathrm{Ag} / \mathrm{AgCl} / \mathrm{GO}$ electrode had an excellent responding time and it could be stable for long time (5 days). It is clearly shown that the fabricated electrode can be used as a

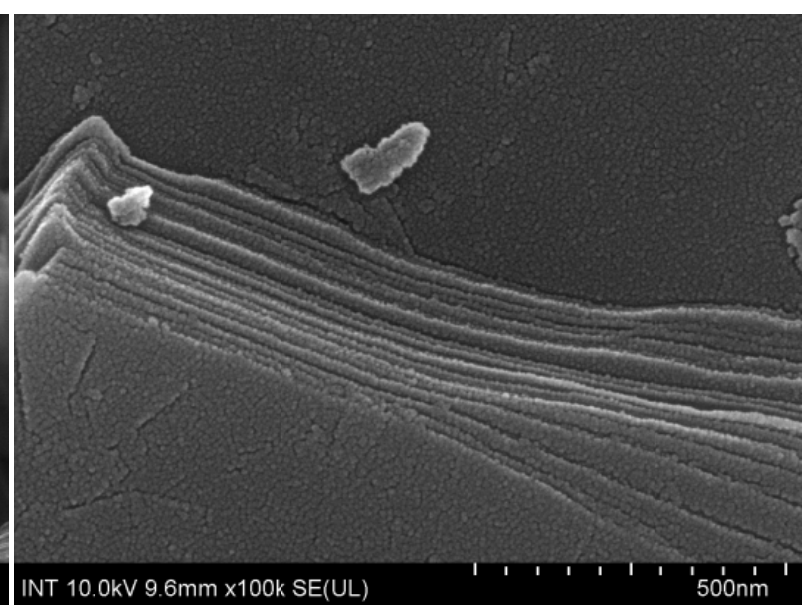

Fig. 3 The surface morphology of the electrode as observed using FE-SEM. 

Potentiometric Sensors by Graphite Oxide Layer
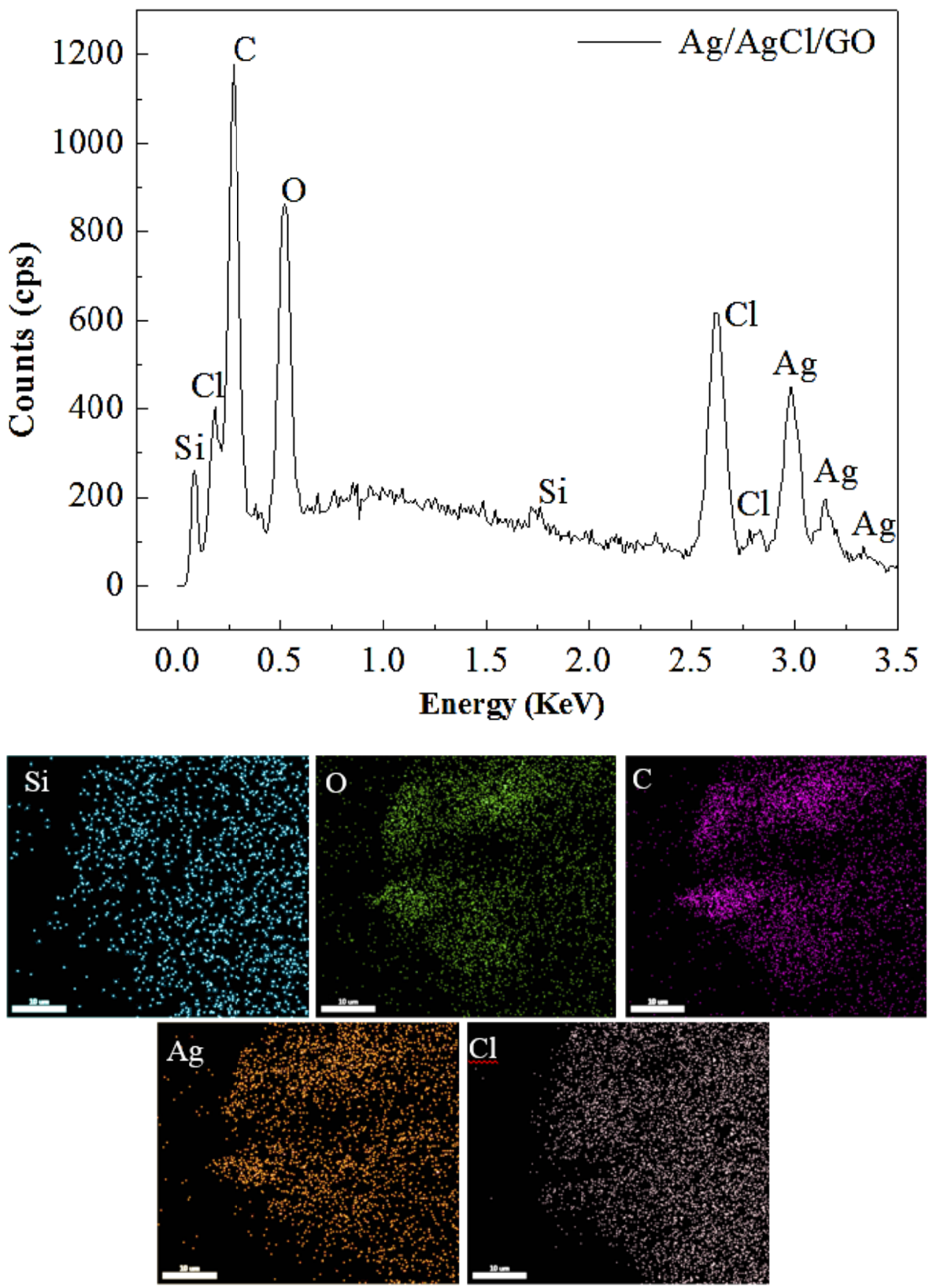

Fig. 4 The EDS spectrum of the Ag/AgCl layer (top) and EDS mapping of Ag, Cl, C, Si, $\mathrm{O}$. 

Potentiometric Sensors by Graphite Oxide Layer

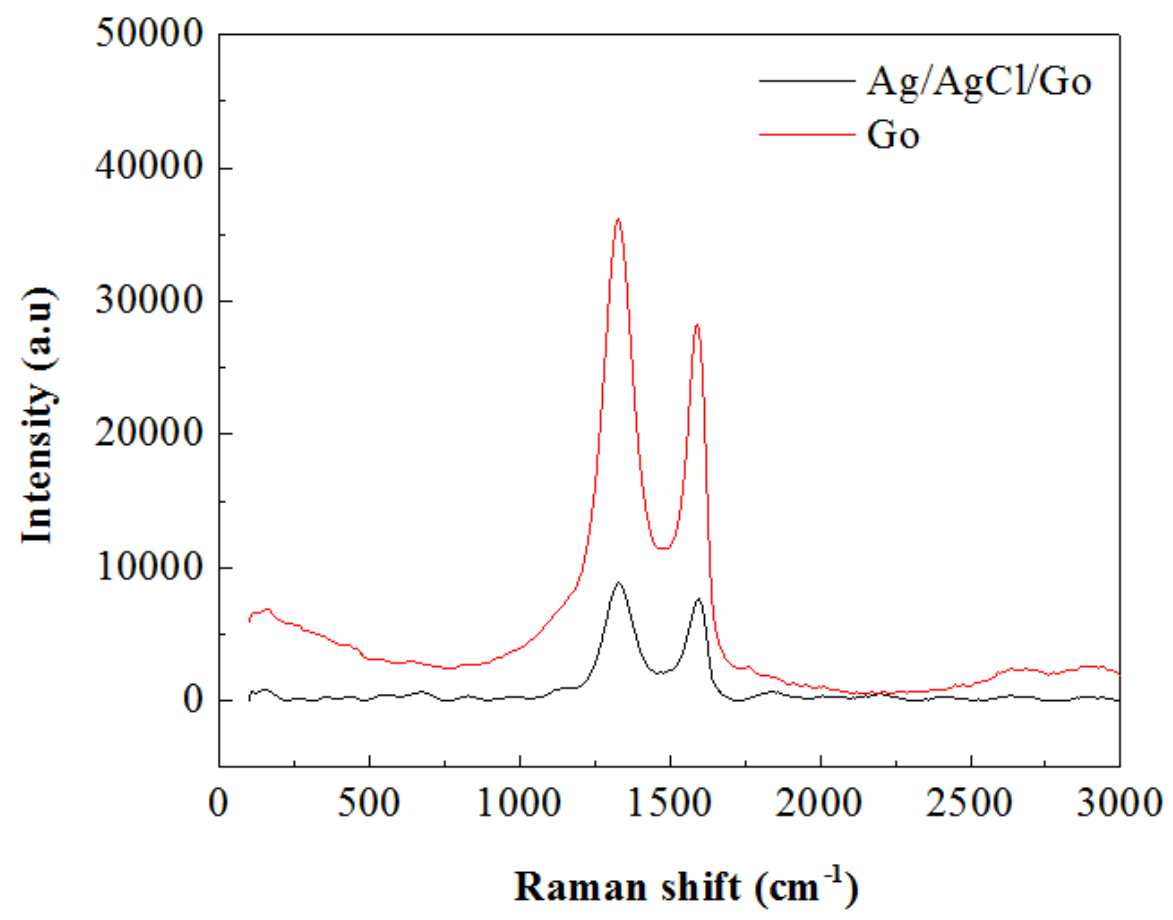

Fig. 5 The Raman spectra of the Ag/AgCl/GO electrode.

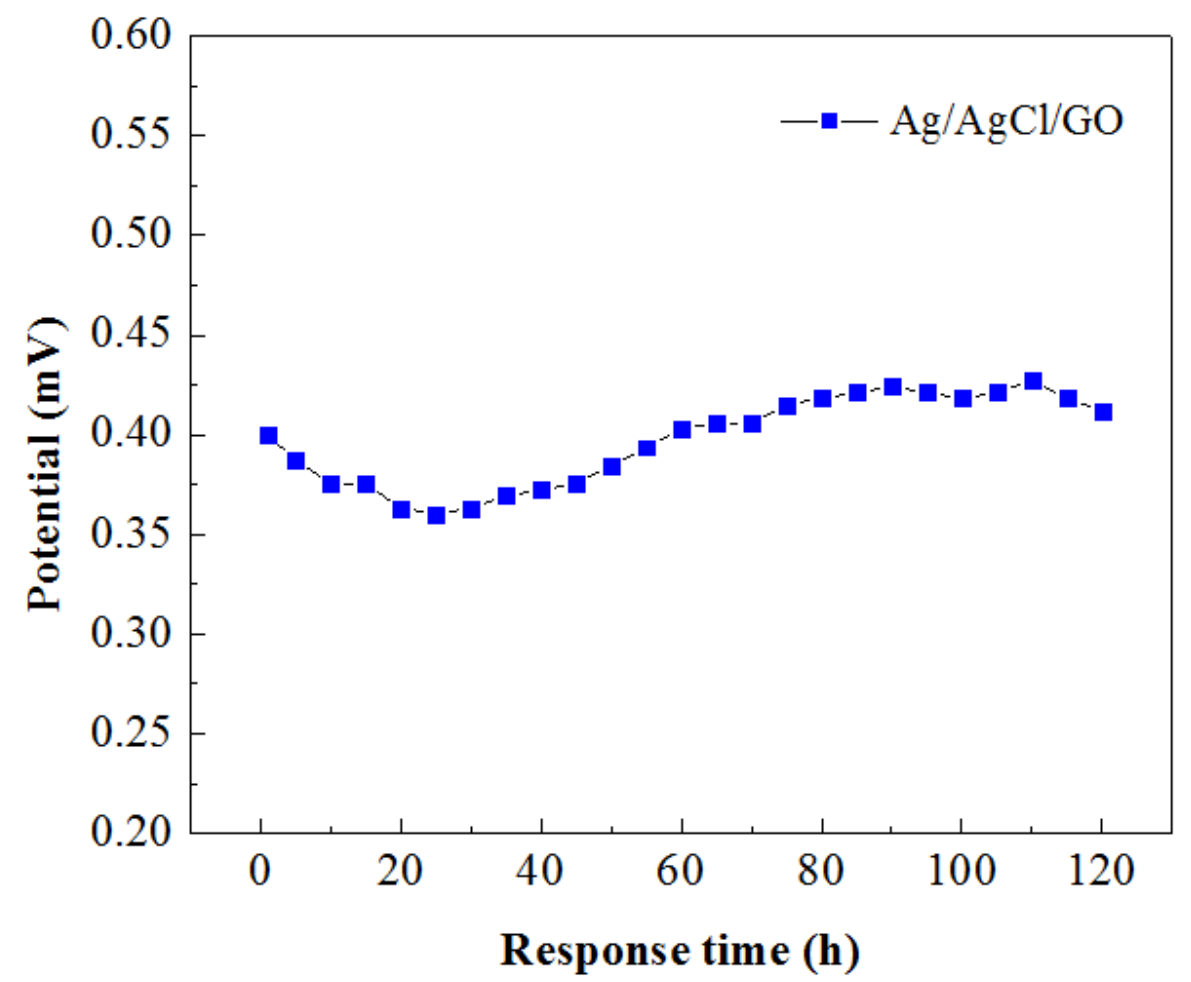

Fig. 6 The responding time and potential of the fabricated electrode were measured in a $3 \mathrm{M} \mathrm{KCl}$ solution over 5 days. 


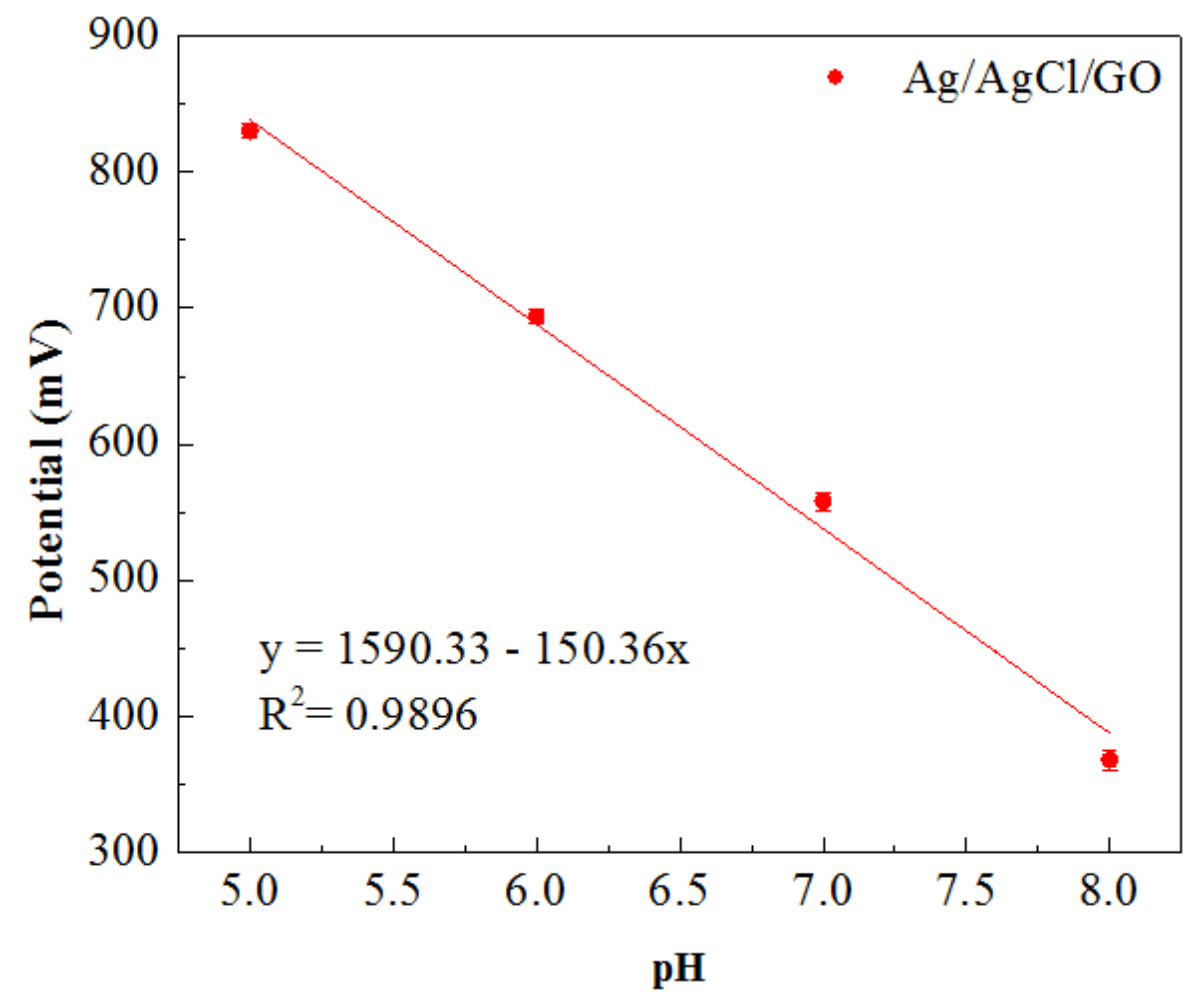

Fig. 7 The potential values of the Pt chips with the Ag/AgCl/GO electrode as the reference electrode.

reference electrode in the potentiometric sensor and provide a good signal.

\subsection{Effect of $p H$ on the Fabricated Electrode}

The effect of $\mathrm{pH}$ on the fabricated electrode was investigated in the solutions with $\mathrm{pH}$ varying from 5-8. The fabricated electrode was dipped in the $\mathrm{pH}$ solutions. The potentials were measured versus the fabricated $\mathrm{Ag} / \mathrm{AgCl} / \mathrm{GO}$ electrode as the reference electrode and the platinum electrode was used as the working electrode. The potential response was plotted (Fig. 7). The operation was performed for $60 \mathrm{~s}$ for every electrolyte solution at temperature of $30 \pm 2{ }^{\circ} \mathrm{C}$.

The potential respond of fabricated electrode exhibited a linear response in $\mathrm{pH}$ ranges (5-8). The sensitivity was calculated to be $-150.36 \mathrm{mV} / \mathrm{pH}$ and the linear correlation coefficient was greater than 0.9899 .

\section{Conclusion}

In this article, a thin layer of GO as protective layer was fabricated on top of the surface of the $\mathrm{Ag} / \mathrm{AgCl}$ electrode by a simple technique. With the presence of the GO layer, the physical (durability) and the electrochemical properties of the fabricated $\mathrm{Ag} / \mathrm{AgCl}$ electrode were enhanced. With all these results, the fabricated $\mathrm{Ag} / \mathrm{AgCl} / \mathrm{GO}$ electrode showed a good sight that it could be used as a planar reference electrode in potentiometric sensor.

\section{Acknowledgements}

The authors highly appreciate the financial support of First Project under the grant Number 09/FIRST/2a/INT.

\section{Reference}

[1] Wang, Y., et al. 2008. "Electrochemical Sensors for Clinic Analysis.” Sensors 8 (4): 2043-81.

[2] $\mathrm{Hu}$, J., et al. 2015. "All-Solid-State Reference Electrodes Based on Colloid-Imprinted Mesoporous Carbon and Their Application in Disposable Paper-Based Potentiometric Sensing Devices." Analytical Chemistry 87 (5): 2981-7. 
[3] Lee, J.-H., et al. 2009. Needle-Type Multi-analyte MEMS Sensor Arrays for in Situ Measurements in Biofilms. pp. 115-45.

[4] Lee, J.-H., et al. 2007. "MEMS Needle-Type Sensor Array for in Situ Measurements of Dissolved Oxygen and Redox Potential." Environmental Science \& Technology 41 (22): 7857-63.

[5] Toczyłowska-Mamińska, R., Dybko, A., and Wróblewski, W. 2006. "All-Solid-State Miniaturised Planar Reference Electrodes Based on Ionic Liquids." Sensors and Actuators B (Chemical) 115: 552-7.

[6] Rius-Ruiz, F. X., et al. 2011. "Solid-State Reference Electrodes Based on Carbon Nanotubes and Polyacrylate Membranes." Analytical and Bioanalytical Chemistry 399 (10): 3613-22.

[7] Wyglądacz, K., et al. 2002. "Design of Miniaturized Nitrite Sensors Based on Silicon Structure with Back-Side Contacts." Sensors and Actuators B (Chemical) 83: 109-14.

[8] Suzuki, H., et al. 1998. "Problems Associated with the Thin-Film $\mathrm{Ag} / \mathrm{AgCl}$ Reference Electrode and a Novel Structure with Improved Durability." Sensors and Actuators B (Chemical) 46: 104-13.

[9] Kim, T. Y., Hong, S. A., and Yang, S. 2015. "A Solid-State Thin-Film Ag/AgCl Reference Electrode Coated with Graphene Oxide and Its Use in a pH Sensor." Sensors 15 (3): 6469-82.

[10] Huang, I. Y., Huang, S., and Lo, L.-H. 2003. "Improvement of Integrated $\mathrm{Ag} / \mathrm{AgCl}$ Thin-Film Electrodes by KCl-Gel Coating for ISFET Applications." Sensors and Actuators B Chemical 94: 53-64.

[11] Brewer, P. J., Leese, R. J., and Brown, R. J. C. 2012. “An Improved Approach for Fabricating $\mathrm{Ag} / \mathrm{AgCl}$ Reference Electrodes.” Electrochimica Acta 71: 252-7.

[12] Valdés Ramírez, G., et al. 2011. "Design and Construction of Solid State $\mathrm{Ag} / \mathrm{AgCl}$ Reference Electrodes through Electrochemical Deposition of $\mathrm{Ag}$ and $\mathrm{AgCl}$ onto a Graphite/Epoxy Resin-Based Composite. Parte 1: Electrochemical Deposition of $\mathrm{Ag}$ onto a Graphite/Epoxy Resin-Based Composite." International Journal of Electrochemical Science 6 (4): 206.

[13] Zielińska, R., et al. 2002. "All-Solid-State Planar
Miniature Ion-Selective Chloride Electrode." Analytica Chimica Acta 451: 243-9.

[14] Idegami, K., et al. 2010. "Fabrication and Characterization of Planar Screen-Printed $\mathrm{Ag} / \mathrm{AgCl}$ Reference Electrode for Disposable Sensor Strip." Japanese Journal of Applied Physics 49 (9): 097003.

[15] Cranny, A., et al. 2011. "Screen-Printed Potentiometric $\mathrm{Ag} / \mathrm{AgCl}$ Chloride Sensors: Lifetime Performance and Their Use in Soil Salt Measurements." Sensors \& Actuators A Physical 169: 288-94.

[16] Diamond, D., et al. 1994. "Evaluation of a New Solid-State Reference Electrode Junction Material for Ion-Selective Electrodes.” Electroanalysis 6: 962-71.

[17] Desmond, D., et al. 1997. "Evaluation of Miniaturised Solid State Reference Electrodes on a Silicon Based Component." Sensors and Actuators B (Chemical) 44: 389-96.

[18] Shinwari, M. W., et al. 2010. "Microfabricated Reference Electrodes and Their Biosensing Applications." Sensors 10 (3): 1679-715.

[19] Nolan, M. A., Tan, S. H., and Kounaves, S. P. 1997. "Fabrication and Characterization of a Solid State Reference Electrode for Electroanalysis of Natural Waters with Ultramicroelectrodes.” Analytical Chemistry 69 (6): 1244-7.

[20] Kim, H. R., et al. 2004. "Enhancement of Physical and Chemical Properties of Thin Film $\mathrm{Ag} / \mathrm{AgCl}$ Reference Electrode Using a Ni Buffer Layer." Sensors and Actuators B (Chemical) 97: 348-54.

[21] Schöning, M. J. 2005. “'Playing around' with Field-Effect Sensors on the Basis of EIS Structures, LAPS and ISFETs." Sensors 5 (3): 126-38.

[22] Nguyen, T. S. V., Thien Dien To, T. M. H., Doan, T. C. D., and Dang, C. M. 2018. " $\mathrm{Ag} / \mathrm{AgCl}$ Film Electrodes Coated with Agarose Gel as Planar Reference Electrodes for Potentiometric Sensors." Universal Journal of Materials Science 6 (5): 148-54.

[23] Wang, Y., Sun, L., and Fugetsu, B. 2013. "Morphology-Controlled Synthesis of Sunlight-Driven Plasmonic Photocatalysts Ag@AgX $(\mathrm{X}=\mathrm{Cl}, \mathrm{Br})$ with Graphene Oxide Template." Journal of Materials Chemistry A 1. 